\title{
Sustaining Student Engagement - Successes and Challenges of a Virtual STEM Program for High School Students
}

\author{
Kelli Qua ${ }^{1,2}$, Raza Haider ${ }^{3}$, Damian J. Junk ${ }^{4}$, and Nathan A. Berger ${ }^{4,5,6,7}$ \\ ${ }^{1}$ Departments of General Medical Sciences, ${ }^{3}$ Physiology and Biophysics, ${ }^{5}$ Biochemistry, ${ }^{6}$ Genetics and Genome Sciences, and ${ }^{7}$ Medicine; ${ }^{2}$ Center for Medical \\ Education; and ${ }^{4}$ Case Comprehensive Cancer Center, Case Western Reserve University School of Medicine, Cleveland, $\mathrm{OH}$ \\ Keywords: STEM, pipeline program, research immersion, scientific opportunity, underrepresented minority high school students, virtual programming \\ Publication Date: August 30, 2021 \\ DOI: https://doi.org/10.15695/jstem/v4i3.09
}

\begin{abstract}
Case Western Reserve University's School of Medicine and Comprehensive Cancer Center coordinate indepth research immersion STEM programs to engage high school students in biomedical research and encourage pursuit of careers in health-related research and clinical care. Due to COVID-19, the 2020 programs were delivered entirely virtually. Student and faculty perceptions of the virtual experience were evaluated using surveys and focus groups. Ninety percent of students felt the virtual program met expectations. Student rankings for programmatic components that could remain virtual in future years showed a preference for highly interactive activities, especially mentorship and dialogue-based activities like discussions of science in the news. Ninety-seven percent of faculty agreed students' scientific knowledge improved. Faculty commented that certain research projects (e.g., data analysis, literature reviews) were highly appropriate for a virtual program, but that the lack of hands-on laboratory activities was challenging. Increased individual attention, flexibility, and independence were hailed as strengths of the virtual program. These findings identify activities that sustain student interest in biomedical, healthcare, and cancer related research using a virtual medium and indicate mentorship and interactive discussion-based activities enhance virtual education. Moreover, the results support incorporation of interactive online pedagogical approaches to enhance student engagement virtually and in-person.
\end{abstract}

\section{INTRODUCTION}

In 2010 the federal government endorsed a national need to increase the presence of science, technology, engineering, and mathematics (STEM) educational programs for secondary school students (National Science Foundation, 2010). Around the same time, the Academic Competitiveness Council reported that only $17 \%$ of federally funded STEM programs focused on K-12 students (U.S. Department of Education). The Case Western Reserve University (CWRU) School of Medicine (SOM), a leading research institution located in Cleveland, Ohio, is home to the Case Comprehensive Cancer Center (Case CCC). The CWRU SOM and the Case CCC coordinate two highly integrated STEM programs to engage high school students in immersive biomedical research and encourage their pursuit of careers in health-related research and clinical care: the philanthropically supported Scientific Enrichment Opportunity (SEO) program, which has operated for 17 years; and the Youth Enjoy Science (YES) program, now in its fourth year, which is supported by an R25 training grant from the National Cancer Institute. The SEO/YES programs have shown the importance of providing opportunities for students from under-represented minorities to experience STEM education (Qua et al., 2019) and of introducing science-motivated high school students to faculty and near peer mentors as role models (Qua et al., 2020). While students in the NCI sponsored YES program are mainly underrepresented minorities and those in the SEO program represent a broader distribution of regional students, the two programs are operationally fully integrated.

The value of direct, hands-on participation in scientific research, accompanied by individualized mentoring, to increase pursuit of biomedical research and health care education and careers, by high school students, in general, and by underrepresented minorities in particular, has previously been described. (Winkleby, 2007; Qua et al., 2020). In previous years, high school students were immersed in in-person laboratory research, conducting independent research projects with individual faculty members as research mentors. Students were encouraged to interact regularly with research mentors, to read deeply about their own research projects 
and to learn about the research process by becoming members of the "laboratory family". Students participated weekly in Lunch and Learn Seminars, where distinguished STEM faculty members of CWRU SOM and Case CCC introduced their research and discussed their own career development. Students also participated weekly in a Near Peer Mentoring program, in which they met in small groups with Case SOM MD-PhD students to discuss science, stress-related-/ psycho-social issues, and coping strategies. All students prepared an abstract, a formal poster, and participated in a capstone poster presentation of their work occurring in the SOM lobby, attended by mentors, other CWRU faculty, family, and community leaders. Descriptions of the overall SEO/ YES program and the near peer mentor component have previously been described. (Qua et al., 2020a; Qua et al., 2020b)

In response to the pandemic, the program was adapted to a totally virtual format, using zoom technology. To design the new virtual format, we relied primarily on our previous 17-year experience with high school students, indicating that our most successful and well-received programs were those that were highly engaging and interactive, that involved active versus passive learning, that stimulated student question and answers and that encouraged students to think and interact on-the-spot. The programmatic changes allowed us to investigate a virtual STEM learning experience based on high school student and faculty preceptor evaluations and recollections. The objectives of this manuscript are to: (1) describe the virtual program components, and (2) investigate perceptions of the virtual research experience in comparison to the 2019 in-person programs. This analysis will identify principles of virtual programming that can effectively sustain student interest in remotely delivered STEM pipeline programs and should be incorporated into future programs.

\section{METHODS}

Participants. In 2020, as in past years, students from Cleveland-area high schools were invited to apply for the SEO/ YES programs. Students were required to be at least 14 years old and to have a grade point average of 3.0 or higher. Students provided a personal statement on career goals, interest(s) in science and cancer, and reasons for wanting to participate in the program, as well as their high school transcripts and two letters of recommendation (from their science teacher and guidance counselor). Student applications were reviewed by a group of high school guidance counselors and medical school faculty who determined the final list of students to be accepted. There were no changes in application or selection processes associated with pandemic protocols, except that evaluations and selections were conducted by Zoom.

Adapting Program Components. In pre-pandemic years the SEO/YES programs were focused on intense individual laboratory research immersion, supplemented by seminarand large class-type approaches to STEM education. In response to the strong desire of many students to participate in summer research programs, despite the pandemic, and to the prohibition of having students in campus facilities during the pandemic, we rapidly converted the 2020 programs to a completely virtual, Zoom-based format. Realizing that most high schools had already converted to virtual education approaches, where students were suffering from Zoom fatigue, we committed to employing as much individual interaction as possible between students and faculty, and to utilizing active as opposed to passive delivery approaches to learning. Items 1-4, described in the Programmatic Components section below, were pre-existing components of our programs that were adapted to virtual delivery or removed. Items 5-9 were new components that we introduced this year and have thus only ever delivered remotely.

1. Virtual Research. In previous years, the major component of our programs was delivered as a two-month research immersion; each student was assigned to an individual mentor and laboratory, where he/she conducted an independent, hands-on, mentor-guided research project that culminated in writing an abstract to be published in an annual program proceedings booklet. Students also prepared a research poster which was presented at a capstone event attended by fellow students, faculty, family members and community leadership.

In response to the pandemic, the traditional research immersion described above was converted to be virtual. Each student was still paired with an individual faculty mentor, based on students' interests as indicated in their applications. Mentors and students were asked to communicate with each other at least three times per week by Zoom or by phone. Mentors were asked to initially orient students to their area of scholarship, assign materials for students to become broadly familiar with the field, and then work with the student to identify a research project to be carried out during the remainder of the summer. In general, research projects took one of two approaches. In some cases, mentors provided students with laboratory data and guided them through analysis, hypothesis development and evaluation. Returning students were sometimes able to engage with their own data generated during the previous year. In other cases, mentors and students developed a project in which they identified a topic, proposed a hypothesis, and then conducted literature review-based research to support or refute the hypothesis they developed. Students were encouraged to use remote technology to attend laboratory meetings and interact with individual lab members.

Students were expected to prepare an abstract describing their research to be published in the annual program pro- 
ceedings book and to write a scientific manuscript describing their summer research activities. As a capstone event, each student prepared a scientific poster and a five-minute pre-recorded video presentation. These were assembled into an end of program poster symposium during which students and guests were able to view the videos and engage in online question-and-answer sessions. A group of MD-PhD students evaluated mentor recommendations, student abstracts, video presentations and responses to questions to identify students to receive prizes for Best Scientific Presentation and Strongest Scientific Growth.

2. Lunch and Learn Seminars. These are a series of seminars provided twice weekly by different expert faculty members to expose students to the breadth of research expertise at Case SOM and the Case CCC. Each faculty member was asked to cover three topics: 1- Briefly explain their academic discipline; 2- Describe their own career trajectory; 3- Describe their scientific research and scholarship. All presentations were followed by a Question-and-Answer session. In previous years, students were provided lunch for these in person seminars. During the pandemic, seminars were still conducted at noon without providing lunch.

3. Near Peer Mentor Program. These are weekly sessions in which $\mathrm{MD}-\mathrm{PhD}$ students met with small groups of high school students to discuss issues regarding stress and develop coping strategies. The MD-PhD students were provided an opportunity to meet with a high school guidance counselor to educate themselves in developing strategies to connect with and guide students. In previous years, groups met in person and were provided with lunch. During this past year, all sessions were conducted by Zoom interactions.

4. Book Club. At the beginning of each summer, all students were provided with a book selected for its relevance to their age, academic level, and social challenges. Examples of books utilized in this program include The Curious Incident of the Dog in the Night-Time by Mark Haddon; Story of a Girl by Sara Zarr; We Beat the Street by Drs. Sampson Davis, George Jenkins and Rameck Hunt; and One of Us is Lying by Karen McManus. At the end of the summer, with guidance from an underrepresented minority faculty member, students participated in a book review to analyze its relevance to their own experiences, and the insights they gained regarding career development. This activity was successful in pre-pandemic years, however, since it was limited to only one interactive session during the summer program, it was discontinued in 2020 and replaced by the weekly Science in the News discussions described below.

5. Electronic Learning Modules. Each week students were assigned two Electronic Learning Modules, approximately

7. Science in the News. On a weekly basis, students were assigned articles from the news that reported on the scientific basis of current events pertinent to their communities. Interactive discussions were led by an underrepresented minority faculty member to develop a more scientific understanding of the events and their impacts. Topics included: the environmental effects on prenatal development and neonatal health and mortality; the Bayer $\$ 10$ billion settlement to resolve the lawsuit about weed killer carcinogenesis; concepts of race, racism, and their impact on healthcare inequities; COVID-19 infections, evidence, and reasons for ethnic differences; and the pandemic-associated rationale for school openings or remote delivery. An interesting approach to the school opening debate was to ask students to discuss issues from the viewpoint of the different stakeholders, for example students, teachers, principals, star athletes seeking college scholarships, bus drivers, parents, public health officials, students receiving school-based food supplements, etc.

8. Career Café Meetings. Each week students met with one of our faculty members who discussed different careers in biomedical research and healthcare delivery. These sessions were usually delivered in a highly interactive fashion. To the extent possible, we identified faculty who were underrepresented minority women with potential to serve as role models. Career paths discussed included those in molecular biology, public health and preventative medicine, family practice, surgical oncology, medical oncology, pediatric oncology, neurodegenerative diseases, tumor immunology, hematology/oncology, and hematopoietic stem cell transplantation.

9. Writing Workshops. Reports from the national Center for 
Education Statistics indicate that only $27 \%$ of the nation's 12 th graders write at proficient or above levels, whereas $21 \%$ were below basic proficiency and $52 \%$ showed only partial mastery of writing skills. Results were worse among underrepresented minorities and among urban vs. suburban students. (NCES, 2012, Goldstein, 2017) These deficiencies were also readily apparent in student essays included in their SEO/YES program applications. Acknowledging the dire needs of many of these high school students to improve their reading comprehension and writing skills, we worked with the CWRU English Department to enlist a group of teaching assistants and junior faculty to meet regularly with small groups of students to focus on reading comprehension tools for searching scientific literature and preparation of scientific abstracts, research papers, and college application essays. These meetings occurred twice a week, with one devoted to providing guidance sessions and the other structured as a counseling session. An important component of this program was instructor-guided opportunities for students to read and critique each other's writings.

Measures. Copies of all measures described below are provided in Appendix A. The instruments provided are from the summer of 2020. Previous iterations of the survey are similar but updates to each instrument are made on a yearly basis.

Post-Program Surveys. In previous years two post-program surveys were used to gather information upon completion of the SEO/YES programs. Students completed a 21-item end of program evaluation that recorded their preferences of various components of the program, areas for improvement, overall stratification, and their plans for college. Faculty preceptors completed a separate 16-item post-program survey which asked them to evaluate student preparedness, improvement, and performance. Post-program surveys used Likert-scales, multiple choice, rank order, and free-text responses. Items to address virtual learning were added to both the student and faculty surveys.

Focus Group. A semi-structured focus group guide consisting of three questions with additional probing questions to encourage elaboration was also administered. Questions focused on students' overall involvement in the summer program, descriptions of the experience with their near peer and faculty mentors, and feedback on program components.

Procedures. This study was approved by the CWRU IRB (IRB \#201920701). Students, parents, and faculty received copies of the informed consent documents. Participation in any survey or focus group was voluntary. All surveys were sent using email addresses through Qualtrics. Post-program surveys were sent within four days of the program end date, with up to two reminders sent to follow-up with potential re- spondents. Email addresses were removed from the dataset prior to analysis and were only used for the purpose of sending reminders. Focus groups with high school students were conducted by the program evaluator (KQ) approximately one week after the end of the program. In 2020, focus groups were conducted via Zoom.

Data Analysis. Data were analyzed via a mixed-methods approach. Descriptive and inferential statistics of closed-response items were analyzed using IBM SPSS Version 27. Chi-square tests were employed to investigate differences in the distribution of responses between 2019 and 2020. Focus group transcripts and open-responses items were analyzed using an inductive content analysis using NVivo 12 software. A study team member developed inductive analytic codes, guided by the content of survey items and focus group prompts and the Standards for Reporting Qualitative Research (O'Brien et al., 2014). Codes were reviewed by a second researcher who was not directly involved with data collection or affiliated with the SEO/YES program (YZ). A singular codebook was created for the analysis of all qualitative data and was aligned to the survey question content. These analyses were used to develop an understanding of student and faculty experiences and perspectives regarding participation in the SEO/YES programs during 2019 and 2020.

\section{RESULTS}

High School Student Participation. In 2020, 150 students applied to the SEO and YES programs, an $87.5 \%$ increase in applicants compared to the previous year ( 80 applicants in 2019). In 2020, 80 students were accepted, and 71 agreed to participate after being informed that the program would be delivered virtually. The number of participants during the previous year's in-person program was similar (63 students accepted). As explained in the Discussion, this increase occurred without any change in our marketing approach. An overview of participant demographics is reported in Table 1.

Overall Perceptions. In 2019 the student response rate to the post-program survey was $54 \%$ compared to $41 \%$ in 2020 . In 2020 close-ended survey items showed $81 \%$ of student respondents felt that the virtual learning format was an effective experience. In $2020,90 \%$ of students indicated the program met their expectations compared to $97 \%$ the previous year; this was not significantly different. Each year students are asked to order program components according to their preference (Table 2). While the top three preferred activities were similar both years, their order differed. In 2019 students most preferred the Research Project. However, in 2020, Student-Mentor Interactions and Near Peer Mentor Meetings supplanted the Research Project. Two new initiatives, Writ- 
Table 1. SEO/YES Student Demographics for 2019 and 2020.

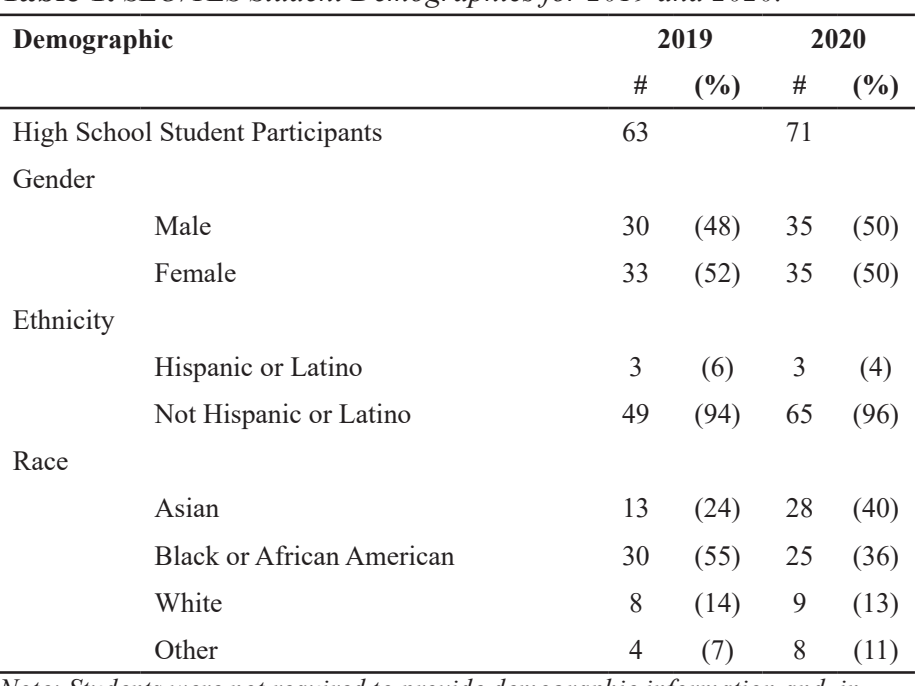

Note: Students were not required to provide demographic information and, in some instances, did not provide a response. Values reported in this table are valid (non-missing) percent.

ing Workshops and Science in the News discussions were preferred within the top half of activities for 2020 .

Students were surveyed regarding their overall learning during the programs. A significant improvement was noted through the close-ended survey items regarding the proportion of students reporting increased knowledge of cancer risk factors and disparities this year (100\%) compared to 2019 $(72 \%)\left(X^{2}(1)=8.96, \mathrm{p}=.003\right)$. The following differences were not significant: In $2019,94 \%$ of students reported the program increased their knowledge in health and health science compared to $100 \%$ in 2020 ; and $75 \%$ of students reported increased knowledge in cancer compared to $93 \%$ in 2020 (Figure 1).
Table 2. Student Preference of Program Activities.

\begin{tabular}{lcc}
\hline Program Components & 2019 Preference & 2020 Preference \\
\hline Student Mentor Interactions & 2 & 1 \\
Near Peer Mentor Meetings & 4 & 2 \\
Research Projects & 1 & 3 \\
Writing Workshops & N/A* & 4 \\
Science in the News & N/A* & 5 \\
Career Café Meetings & 5 & 6 \\
Lunch and Learn Seminars & 3 & 7 \\
Learn to Beat Cancer & N/A* & 8 \\
Electronic Learning Modules & N/A* & 9 \\
\hline
\end{tabular}

*Note: N/A indicates that a program component was new in 2020 and therefore has no prior comparisons to 2019. These preferences are ranked in order of 2020 preference (right most column).

Closed-ended survey items indicated student overall interest in specific career areas was not significantly different between 2019 and 2020. In 2019, 84\% of students had an increased interest in pursuing a career in health science or health care and $53 \%$ in cancer research. In $2020,85 \%$ of students reporting an increased interest in health science or health care careers and $63 \%$ in cancer research.

Virtual Learning. In 2020 students were asked what program activities they recommend could be incorporated into future programs as virtual activities. Close-ended survey items showed that more than half of students highly recommended online student-mentor interactions and near peer mentor meetings could continue to be remotely delivered (Table 3 ). About half of students recommended that the Science in the News discussions and Writing Workshops could remain vir-

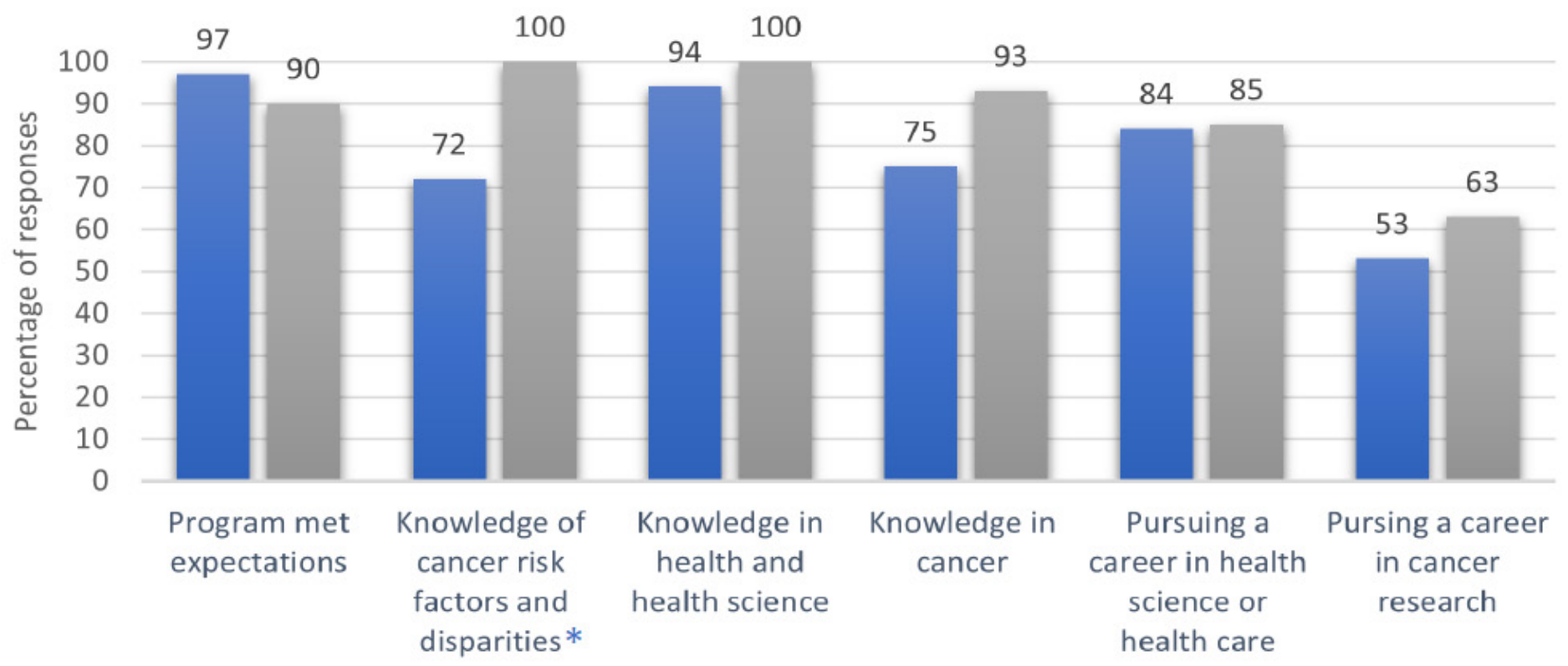

$*_{p}<.05$

Figure 1. Student responses to program satisfaction, increased knowledge, and career interest survey items. 
Table 3. Student Perceptions of Virtual Learning Activities.

\begin{tabular}{lc}
\hline Program Components & $\begin{array}{c}\text { Percent of Participants } \\
\text { Recommending Virtual } \\
\text { Continuation }\end{array}$ \\
\hline Student-Mentor Interaction & $55 \%$ \\
Near Peer Mentor Meetings & $55 \%$ \\
Science in the News & $42 \%$ \\
Writing Workshops & $42 \%$ \\
Career Café Meetings & $32 \%$ \\
Research Project & $32 \%$ \\
Learn to Beat Cancer & $23 \%$ \\
Lunch and Learn Seminars & $19 \%$ \\
Electronic Learning Modules & $19 \%$ \\
\hline
\end{tabular}

tual. One third of students recommended Research Projects and Career Café Meetings could remain online. Less than one quarter of students recommended continued virtual delivery of Learn to Beat Cancer, Lunch and Learn Seminars, and the Electronic Learning Modules.

Qualitative data provided evidence of the successful adaptation of program components to the virtual platform, as well as some challenges with the 2020 virtual programs (Table 4). Nine students participated in two focus groups and all survey respondents provided at least one response to an open-ended question. Four themes emerged from the students: socializing, hands-on experience, online access, skills and/or career mentorship. Some students noted that they were able to more widely share their research projects and learn more about each other's projects through the virtual platform. One student stated the virtual research capstone

Table 4. Students Perceived Benefits and Challenges Associated with Virtual Learning.

\begin{tabular}{|c|c|c|}
\hline Theme & $\begin{array}{l}\text { Percentage of } \\
\text { Comments* }\end{array}$ & Example Quotation \\
\hline $\begin{array}{l}\text { Socializing } \\
\text { Students missed connecting } \\
\text { with other high-schoolers and } \\
\text { lab members in person. }\end{array}$ & $30 \%$ & $\begin{array}{l}\text { "I was not able to socialize with } \\
\text { other students who have similar } \\
\text { interests. I think that it was } \\
\text { more difficult to get to know } \\
\text { others in the program." }\end{array}$ \\
\hline $\begin{array}{l}\text { Hands-on Experience } \\
\text { Limited opportunities to } \\
\text { conduct experiments in the lab }\end{array}$ & $27 \%$ & $\begin{array}{l}\text { "It was frustrating not being } \\
\text { able to physically perform } \\
\text { experiments" }\end{array}$ \\
\hline $\begin{array}{l}\text { Students felt they received a } \\
\text { high level of attention from } \\
\text { their research mentors in the } \\
\text { virtual program }\end{array}$ & $24 \%$ & $\begin{array}{l}\text { "Being in the program before, } \\
\text { this year it felt I got more time } \\
\text { talking to my research mentor } \\
\text { than last year. We talked every } \\
\text { week just us two. I was not as } \\
\text { nervous and didn't have to wor- } \\
\text { ry about the rest of the lab" }\end{array}$ \\
\hline $\begin{array}{l}\text { Skills/Careers Mentorship } \\
\text { Students received support to } \\
\text { develop a professional skill } \\
\text { and/or were introduced to a } \\
\text { career of interest to them by a } \\
\text { mentor }\end{array}$ & $19 \%$ & $\begin{array}{l}\text { "I felt like I didn't under- } \\
\text { stand how to write like I was } \\
\text { being asked to and the writing } \\
\text { workshops really helped me to } \\
\text { understand what was expected } \\
\text { in an abstract and now I feel } \\
\text { confident I can write one." }\end{array}$ \\
\hline
\end{tabular}

*Note: Percentages were calculated according to the total number of comments coded.
Table 5. Comparison of Faculty Responses on Preparedness and Improvement 2019-2020.

\begin{tabular}{lcc}
\hline \multicolumn{1}{c}{ Survey Item } & $\begin{array}{c}\text { Faculty } \\
\text { 2019 Responses } \\
(\mathrm{n}=43)\end{array}$ & $\begin{array}{c}\text { Faculty } \\
\mathbf{2 0 2 0} \text { Responses } \\
(\mathrm{n}=34)\end{array}$ \\
\hline $\begin{array}{l}\text { Was your student prepared to participation } \\
\text { in this program? }\end{array}$ & $86 \%$ & $76 \%$ \\
$\begin{array}{l}\text { Were you prepared to participation in this } \\
\text { program? }\end{array}$ & $95 \%$ & $88 \%$ \\
$\begin{array}{l}\text { Did your student's knowledge of scientific } \\
\text { concepts improve? }\end{array}$ & $95 \%$ & $97 \%$ \\
\hline
\end{tabular}

presentations "allowed me to see more of my friends' presentations." Others mentioned the virtual mentor meetings as a great place to get "one on one time" with their research mentors who otherwise might have been distracted by others in the lab. Students also commented on new program components and their successful delivery online. "The online Career Cafés often shone a spotlight on very impressive people who told their own stories that were really inspiring for me." The online writing workshops were the most commented on positive highlight for students. Students felt that "learning how to write research helped me understand the science better" and for many was a skill they highly valued. Students missed the opportunity to socialize with other high school students interested in science. A few students mentioned they missed the ability to socialize with lab members onsite since Zoom meetings were strictly project focused. Several students noted the absence of laboratory experience. While they felt the program was effective, one of the key components of the program is hands-on laboratory experience.

\section{Faculty Preceptor Perceptions.}

Overall. The faculty preceptor response rate was $72 \%$ in 2019 and $64 \%$ in 2020. Faculty respondents were direct research mentors and were not involved in other program components. Faculty were asked to rate the preparedness of the students and themselves in terms of participating in these programs (Table 5). Close-ended survey items indicated a $10 \%$ decrease in faculty feeling their student was prepared for the program between years. Between 2019 and 2020 there was a $7 \%$ decrease in faculty feeling they were prepared to be preceptors. Faculty were also asked to identify increased knowledge of scientific concepts among their students; there was an increase of 2\% between 2019 and 2020. Overall, there was no significant difference between faculty perceptions during the 2020 virtual programs compared to the on-site/in-person 2019 programs.

Virtual Learning. Faculty preceptors were asked four questions, one close-ended and three open-ended items, regarding the impact of COVID-19 on the SEO/YES programs. Sixty-seven percent of the faculty felt that the online format was an effective experience for students. Seventeen faculty 
Table 6. Faculty Responses to the Impact of the Virtual Program in 2020.

\begin{tabular}{|c|c|c|}
\hline Theme & $\begin{array}{l}\text { Percentage of } \\
\text { Comments* }\end{array}$ & Example Quotation \\
\hline Project Conditions & & $\begin{array}{l}\text { "The online format is effective } \\
\text { for the student to get scientific } \\
\text { knowledge or design experi- } \\
\text { ment." }\end{array}$ \\
\hline $\begin{array}{l}\text { Faculty described the effec- } \\
\text { tiveness of the program un- } \\
\text { der the "right" conditions. }\end{array}$ & $43 \%$ & $\begin{array}{l}\text { "My student selected data analy- } \\
\text { sis and was able to complete the } \\
\text { entire project remotely. I was ini- } \\
\text { tially very concerned about the } \\
\text { virtual setting, but the student } \\
\text { amazed me with their ability } \\
\text { to conduct the work outside of } \\
\text { the lab." }\end{array}$ \\
\hline Student Adaptability & & \multirow{2}{*}{$\begin{array}{l}\text { "Working virtually was perfect } \\
\text { as it forced the student to be- } \\
\text { come independent of the mentor } \\
\text { as far as possible and this made } \\
\text { them a more critical thinker and } \\
\text { problem solver." }\end{array}$} \\
\hline $\begin{array}{l}\text { Faculty identified the stu- } \\
\text { dents were highly capable } \\
\text { of adapting to the remote } \\
\text { environment. }\end{array}$ & $31 \%$ & \\
\hline Missed Opportunities & & \multirow[b]{2}{*}{$\begin{array}{l}\text { "Since there was no bench work } \\
\text { by the student in lab, there's no } \\
\text { substantial experimental results } \\
\text { to get better research achieve- } \\
\text { ment." }\end{array}$} \\
\hline $\begin{array}{l}\text { Faculty discussed missed } \\
\text { opportunities for hands-on } \\
\text { research and creating more } \\
\text { personal relationships. }\end{array}$ & $26 \%$ & \\
\hline
\end{tabular}

members provided comments which elaborated upon their response. Seven comments were very positive and mentioned that the online approach coincided well with certain phases of projects and that the students already had the knowledge to use various online platforms and tools (i.e., Zoom). Despite the online platform being effective, preceptors stated "there is no substitute for actual lab experience and hands-on experimentation." Thirty-one out of 34 preceptors provided comments on the challenges they faced working with students virtually. The two largest concerns were communication between the mentors and students and the lack of "substantial experimentation". Related to the impact of remote interactions, five faculty preceptors noted issues including internet speed, "chaotic" home settings, and students' limited attention spans.

Final comments from open-ended survey items revealed that the virtual program worked in certain instances, but not all (Table 6). Projects that were in specific phases of development such as initial literature reviews, data analysis, and writing, were best suited for this approach. One preceptor stated, "I think the program did an excellent job even with a virtual format. I could see that my student has gained substantial experience from reading the literature, thinking through the problem, and writing up a paper." Projects that required collecting data were not as effective at engaging students virtually. Preceptors noted that they "would like to have been able to involve the students more in lab experimentations we were conducting, such as cell culture and western blot. This would have allowed the student to follow up on direct experimental testing of the ideas they generated."

\section{DISCUSSION}

The SEO/YES programs are aimed at introducing high school students, particularly from underrepresented minorities, to STEM fields, especially in medicine and healthcare. By pairing students with scientific research mentors, introducing them to various outstanding faculty for career-oriented interactions, facilitating discussions between students about mental health, their own wellness, and current events, among other activities, these programs show high schoolers how science works and empowers them to consider such careers for themselves. Though the SEO/YES programs' core mission has remained the same since their inceptions, programmatic components have been modified and added based on student feedback to improve the experience. The development of Near Peer Mentor meetings, in which CWRU MD-PhD students congregate weekly with small groups of high school students to talk about stresses, mental health, and coping strategies, is one such example (Qua et al., 2020).

The striking change of an $87.5 \%$ increase in student applications, from 80 in 2019 to 150 in 2020, without any change in our marketing approach, may be attributed to multiple factors, but primarily to the increased program reputation spread by participating students to their schoolmates, by parents to their communities, and by high school science teachers and college guidance counselors. From discussions with students, families and guidance counselors, it is apparent that a perception exists, that participation in the SEO/ YES and our recommendation letters in support of college admission applications, improves student competitiveness for college admissions and scholarships. The possibility also exists that the increased number of applications was contributed to by concerns over the educational quality of courses provided during the tumultuous scheduling associated with the pandemic lockdown.

Originally, the 2020 version of the programs was to be conducted in the same, in-person, highly immersive and interactive format, with five new components added to the curriculum. The COVID-19 pandemic, however, necessitated the programs be adapted to a virtual setting. Discussions and activities had to be delivered via Zoom, research projects no longer included hands-on experimentation, seminars no longer had lunches provided, nor were there extended opportunities for student social interaction. We even eliminated one component that involved the students reading a book that addressed academic and social challenges germane to their ages because it only had one interactive session. Despite these challenges and modifications, students reviewed the $2020 \mathrm{SEO} / Y E S$ programs positively; furthermore, most faculty mentors felt that their students' knowledge of science had improved.

Overall comparison of the 2020 virtual SEO/YES programs relative to its 2019 in-person version showed that the virtual program was successful in maintaining student en- 
gagement, overall learning, research participation, and mentor interactions. As discussed below, we attribute this success to the highly interactive and active learning approaches incorporated into programmatic delivery. A particularly interesting outcome was the observation that in $2019,72 \%$ of students reported increased knowledge of cancer risk factors and disparities, compared to $100 \%$ of students in 2020 . This increased knowledge may be attributed to both increased public exposure as well as expanded coverage of these topics in the virtual delivery of our program. For example, in 2019, cancer prevention and cancer disparities were each addressed in a single Lunch and Learn Seminar, a short question and answer session, and a single Near Peer Mentor meeting. During the 2020 virtual program, disparities and cancer prevention were each addressed in separate Lunch and Learn Seminars and multiple Near Peer Mentor Meetings. In addition, these topics were repeatedly and extensively discussed in an interactive fashion on a weekly basis as part of our Science in the News program and in the Learn to Beat Cancer sessions. Thus, the increased knowledge of cancer prevention and disparities may be consequent to the increased presentation of the content, repetition of the material, and the highly interactive nature of its presentation, ultimately enhancing knowledge acquisition. The increase in knowledge was further accompanied by the development of a new, ongoing community outreach program, in which students apply their knowledge of heath disparities to develop new Community Based Participatory Research in concert with the Case CCC Community Advisory Board.

There were several virtual activities that students recommended could remain virtual in future, in-person programs. About half of students indicated that the Student-Mentor Interactions, the Near Peer Mentor meetings, Science in the News discussions, and Writing Workshops could remain remote. When students were asked about their preference of the program components in 2020, these four activities were within the top five most preferred. This correlation suggests that educational activities that are designed to be highly interactive adapt well to online learning. These preferences may be linked to the characteristics of these program components as interactive learning sessions versus didactic-type instruction. The four most preferred activities were highly student-centered interactions that required equal participation among students and faculty facilitators. None of these activities could have been adequately done without the students' full participation. In contrast, the activities that students felt should be held in-person in future years were not as interactive, being delivered in either lecture-based format, without much student participation, (Learn to Beat Cancer sessions, Career Café meetings, Lunch and Learn Seminars) or in an "online assignment" format that the students completed independently (Electronic Learning Modules).

During the current 2021 SEO/YES Program year, in re- sponse to institutional policy, we have transitioned to a hybrid model with first month being virtual and second month being in-person on-site. As a result of the lessons learned from the 2020 Pandemic Imposed Adaptation to a virtual program, we are continuing to emphasize the highly individual nature of the student-mentor interactions, as well as the small group interactions associated with the Near Peer Mentor Programs and the Writing Workshops. We have accordingly stressed the importance to project mentors of interacting with students several times weekly in a one-on-one format, in addition to engaging their participation in general lab meetings. Based on the more favorable student preference for Science in the News activities, compared to Career Cafes and Lunch and Learn Seminars, we have asked and instructed faculty leading these latter activities to make these sessions more engaging, more highly interactive and relevant to participant's experiences. While these recommendations, to expand student interactions in all components, seem appropriate for future program years, their incorporation as continued regular activities, will depend on annual student and faculty evaluation and approaches to continuous quality improvement as well as results to be reported from similar high school STEM internships that transitioned to virtual programming during the recent past.

Our observations are consistent with previous reports that the power of interaction in education has been noted in multiple previous studies. "Dialogic education" centering on closer student-student, student-teacher, and student-community interactions has been shown to foster improved learning outcomes for students from challenged backgrounds and for special needs students as well (García-Carrón et al., 2018; Racionero and Padrós, 2010). Our study has generated evidence that activities designed with a high degree of interaction can be effectively utilized to positively engage students in a virtual setting.

\section{ASSOCIATED CONTENT}

Supplemental material mentioned in this manuscript can be found uploaded to the same webpage as this the manuscript.

\section{AUTHOR INFORMATION \\ Corresponding Author}

Nathan A. Berger. 216-368-4084.nab@case.edu

\section{Author Contributions}

The manuscript was written through contributions of all authors. All authors have given approval to the final version of the manuscript. 


\section{FUNDING SOURCES}

This project was supported in part by NIH Grants P30CA043703 and R25CA221718.
Winkleby MA. (2007). The Stanford Medical Youth Science Program: 18 years of a biomedical program for low-income high school students. Academic Medicine, 82(2), 139-45.

\section{ABBREVIATIONS}

Case CCC: Case Comprehensive Cancer Center; STEM: Science, Technology, Engineering, and Mathematics; CWRU: Case Western Reserve University; SEO: Scientific Enrichment Opportunity; SOM: School of Medicine; YES: Youth Enjoy Science

\section{REFERENCES}

García-Carrión, R., Molina Roldán, S., and Roca Campos, E. (2018). Interactive learning environments for the educational improvement of students with disabilities in special schools. Frontiers in Psychology, 9, 1744.

Goldstein, D. (2017, August 2). Why Kids Can’t Write. The New York Times. https://www.nytimes.com/2017/08/02/education/edlife/writing-education-grammar-students-children. html

National Center for Education Statistics (2012). The Nation's Report Card Writing 2011 (NCES 2012-470). Institute of Education Sciences, U.S. Department of Education. Washington D.C.

National Science Foundation (US). (2010). Preparing the next generation of STEM innovators: Identifying and developing our nation's human capital. National Science Foundation.

O’Brien B., Harris I., Beckman T., Reed D., and Cook D. (2014) Standards for reporting qualitative research: a synthesis of recommendations. Academic Medicine, 89(9), 1245-51.

Qua, K., Pinkard, O., Kundracik, E. C., Ramirez-Bergeron, D., and Berger, N. A. (2020a). Near peer mentors to address socio-emotional issues among underrepresented minority high school students in research intensive STEM programs: Perceptions of students and mentors. Journal of STEM Outreach, 3(1), 1-8.

Qua, K., Papp, K. K., Junk, D. J., Hooper, M. W., and Berger, N. A. (2020b). Youth Enjoy Science program at the Case Comprehensive Cancer Center: Increasing engagement and opportunity for underrepresented minority students. Ethnicity and Disease, 30(1), 15.

Racionero, S., and Padrós, M. (2010). The dialogic turn in educational psychology. Revista de Psicodidáctica, 15(2), 143162.

U.S. Department of Education. (2007). Report of the Academic Competitiveness Council. Washington, D.C. Retrieved from: http://www.ed.gov/about/inits/ed/competitiveness/ acc-mathscience/index.html 